\title{
THEORETICAL MODELING OF A STEAM POWER CYCLE USING AN INTERACTIVE COMPUTATIONAL TOOL
}

\author{
Cristina Lizarazo ${ }^{1}$, Carlos Acevedo Peñaloza ${ }^{2}$, Guillermo Valencia Ochoa ${ }^{3 *}$ \\ ${ }^{1}$ Mechanical Engineering student, Faculty of Engineering, Grupo de Investigación en Gestión Eficiente de la \\ Energía-kaí, Universidad del Atlántico, Km 7 Vía Puerto, 081007, Barranquilla, Atlántico, Colombia. \\ cristina.lizarazo09@gmail.com. \\ ${ }^{2} \mathrm{Ph} . \mathrm{D}$. Mechanical Engineer, Mechanical Engineering Department, \\ Grupo de Investigación en Diseño Mecánico y mantenimiento, Universidad Francisco de Paula Santander, \\ Avenida Gran Colombia No. 12E-96, Cúcuta, Norte de Santander, Colombia. \\ carloshumbertoap@ufps.edu.co. \\ ${ }^{3} \mathrm{Ph} . \mathrm{D}(\mathrm{c})$. Mechanical Engineer, Faculty of Engineering, Grupo de Investigación en Gestión Eficiente de la \\ Energía-kaí, Universidad del Atlántico, Km 7 Vía Puerto, 081007, Barranquilla, Atlántico, Colombia. \\ guillermoevalencia@mail.uniatlantico.edu.co.
}

\begin{abstract}
This paper presentsan energetic and exergetic analysis for ageneration of turbine work according to the variation of the pressure in the condenser regenerative Rankine cycle, implementing an educational graphical user interface known as Power Cycle version 2.0; that is used as a pedagogical strategy in thefield ofengineering education. The mains objectives were, analyzethe efficiency of first and second thermodynamic law, and the generation of turbine work according to the variation of thecondenser pressure, at three different temperatures in the boiler, as well as analyzing the components of the system to identify and quantify where the exergy destruction was maximum. According to the results in the cases studied, the percentage ratio of the exergydestruction to the total exergy destruction was found to be maximum in the boiler $62.18 \%$, then the turbine $22.79 \%$, and finally $15.03 \%$ in the pumps, the heater and the condenser. On the other hand, the maximum calculated thermal efficiency was $38.34 \%$, while the maximum exergetic efficiency was $62.81 \%$. A significant increase in efficiency of the cycle is obtained by decreasing the pressure in the condenser.
\end{abstract}

Keywords - Exergetic balance, energy balance, efficiency, regenerative Rankine cycle.

\section{INTRODUCTION}

The Carnot cycle is the most efficient of the cycles operating between two specified temperature limits[1]. Therefore, it is natural to first consider this cycle as an ideal cycle prospect for steam power plants. However, it is known that it is not a realistic model for steam power cycles, because is associated with impractical aspects[2]. As a solution to this, the ideal Rankine Cycle was proposed, in which the steam is superheated in the boiler, then taken to a turbine where it produces mechanical energy and losing pressure,after it passes to the condenser and ends up in a pump that will raise the pressure to be introduced it back into the boiler [3].However, modifications have been made to this power cycle, in the present case study it focused on regeneration, in which a regenerator or open feedwater heater is used, this process consists on extracting part of the steam from the turbine to preheat the liquid before it enters the boiler, the above is done in order to increase the efficiency of the cycle and provide a convenient means deairing the feed water to prevent corrosion in the boiler[4]. In general, the performance of thermoelectric power plants is evaluated by means of energetic and exergetic performance criteria based on thermodynamic laws, including electrical power and thermal efficiency[5], [6]. On the other hand, for the study of the second law of thermodynamics, entropy generation is used to evaluate the irreversibility of thermodynamic processes[7]. Many researchers have focused on this field, trying to find the minimal generation of entropy[8], [9]. Bejan [10] explained how to optimize power cycles, minimizing exergetic destruction and the generation of entropy by components. Kotas [11] was dedicated to the study of exergy to explain the efficiency of the second law in power cycles. George y Park [12] discussed how to estimate the avoidable and unavoidable destruction and investment costs associated with compressors, turbines, heat exchangers and combustion chambers. In addition, according to other research [13], [14], it was known that irreversibilities depend not only on the inefficiency of the component studied, but also on the structure of the system and on the inefficiencies of the other components. Although these authors carried out rigorous research in the proposed area, the methods they proposed to perform calculations for the exergetic destructions and the thermal efficiency of the cyclebecome complex and extensive, for this reason, the present 
paper was developed under the implementationof an education software, Power cycle version 2.0, which is friendly with the users and provides the necessary information to carry out studies relating with the energy and exergy balance of different power cycles. In addition, it has been confirmed that the use of educational tools promotes interest in students of engineering courses. [15], [17], which makes the use of some educational software as a complementary option to the traditional approach [18], [20].

\section{METHODOLOGY}

\subsection{Software validation.}

Through the implementation of the Power Cycle Software, the calculations corresponding to the analysis of the first and second law of thermodynamics of a regenerative Rankine cycle were made as shownin the Figure 1, under different operating conditions in order to understand the effect of these on the system studied.

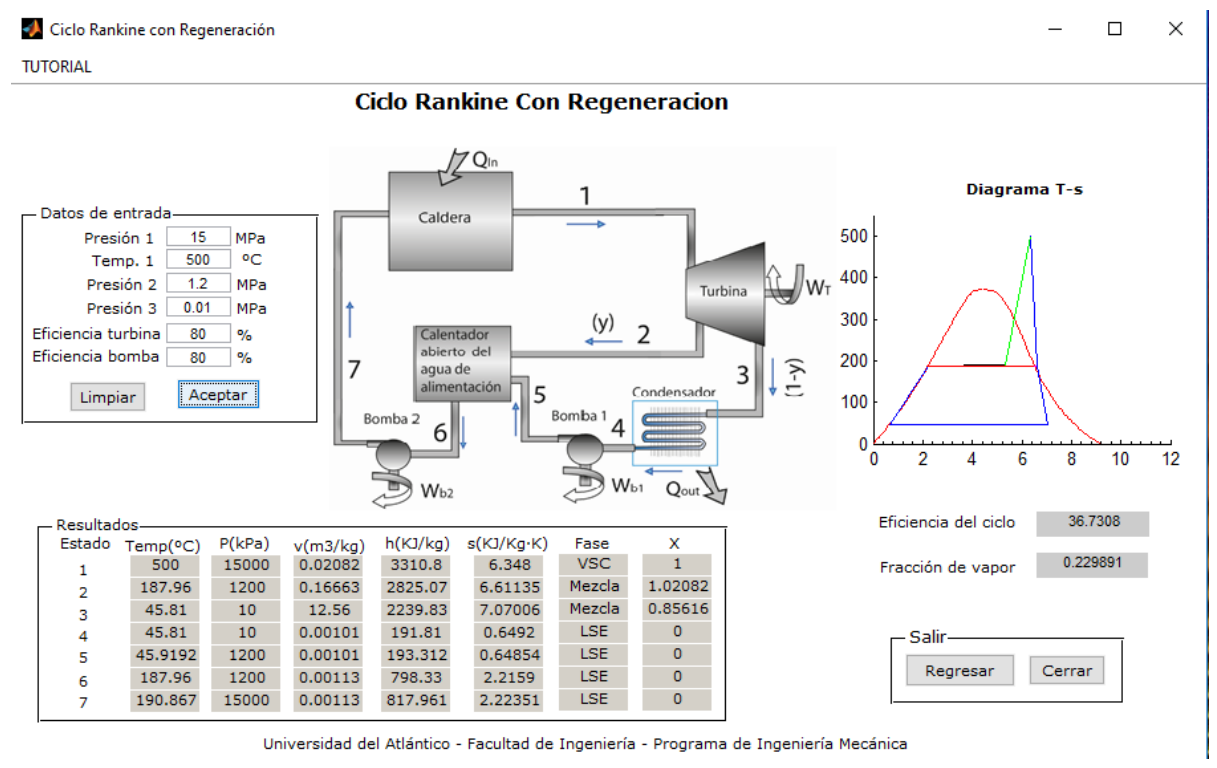

Fig 1. Software validation.

\subsection{Energy balance analysis.}

For the power cycle studied, shown in the Figure 2, it was chosen to work with an isentropic efficiency of $80 \%$,in the turbine and the two pumps. In order to find the thermal efficiency, the respective energy balances for open systems were carried out, this only for independent analysis, in other words by components. In the boiler the input heat was found, (see equation 1); then in the turbine the output work was found, (see equation 2). For the condenser, the output heat was found (see equation 3); and for both pumps 1 and 2, the input works were found (see equations 4 and 5). Finally, in the energy analysis for the open heater the ratio of mass flow through the condenser was found (see equation 6). Subsequently, after getting the previous data, the thermal efficiency of the cycle was found (see equation 7).

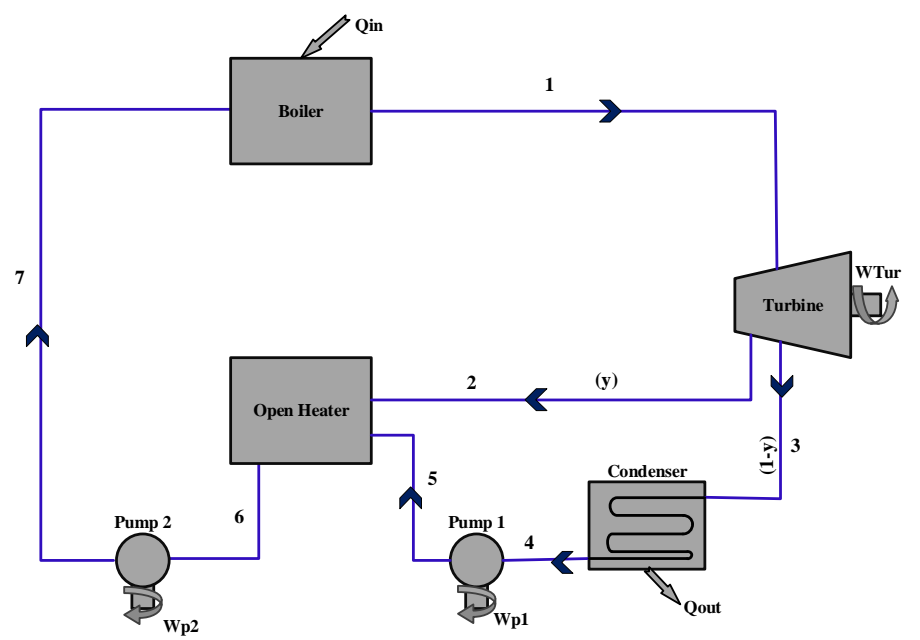

Fig 2. Diagram of the regenerative Rankine cycle. 


\subsection{Exergy balance analysis.}

This analysis was based on the general equation proposed by Cengel[3]. However, when isconsidered by components of the cycle, this equation can vary. In the case of the boiler (see equation 8), there is an input heat, which is given at the border temperature and the other data are known thanks to the Power Cycle software. Similarly, it was made for the following components, for the turbine (see equation 9). The destroyed exergy by the condenser was also calculated (see equation 10), taking into account the mass flow through this. And then the destroyed exergy in the pumps1 - 2 and the open heater, (see equation 11, 12 and 13). Having the calculations described above it is possible to find the efficiency of the second law (see equation 14), and to emit a sustainable concept about the exergy destruction in a regenerative Rankine cycle, varying the condenser pressure in a range from $0.01 \mathrm{MPa}$ to $0.06 \mathrm{MPa}$, with an increase of 0.005 ; at three temperatures in the boiler $500^{\circ} \mathrm{C}, 550^{\circ} \mathrm{C}$ y $600^{\circ} \mathrm{C}$.

TABLE I -Energy and exergy balances for the different components of the cycle.

\begin{tabular}{|c|c|c|c|}
\hline $\begin{array}{l}\text { COMPON } \\
\text { ENT }\end{array}$ & ENERGY BALANCE & & EXERGY BALANCE \\
\hline BOILER & $q_{\text {in }}=h_{1}-h_{7}$ & & $X_{\text {des. } B}=\left(1-\frac{T_{0}}{T_{i n}}\right) q_{i n}+h_{7}-h_{1}-T_{0}\left(s_{7}-s_{1}\right)$ \\
\hline TURBINE & $W_{T}=\left(h_{1}-h_{2}\right)+(1-y)\left(h_{3}-h_{4}\right)$ & (2) & $\begin{array}{c}X_{\text {des-T }}=h_{1}-h_{2}-T_{0}\left(s_{1}-s_{2}\right)+(1-y) \cdot\left(h_{2}-h_{3}\right. \\
-T_{0}\left(s_{2}-s_{3}\right)-W_{T}(9)\end{array}$ \\
\hline CONDENSER & $q_{\text {out }}=(1-y)\left(h_{3}-h_{4}\right)(3)$ & & $X_{\text {des-Co }}=\left(1-\frac{T_{0}}{T_{i}}\right) Q_{i}+h_{7}-h_{1}-T_{0}\left(s_{7}-s_{1}\right)(10)$ \\
\hline PUMP 1 & $W_{P 1}=(1-y)\left(h_{5}-h_{4}\right)$ & $(4)$ & $\begin{array}{c}X_{d e s-P 1}=(1-y)\left(h_{4}-h_{5}-T_{0}\left(s_{4}-s_{5}\right)\right)-W_{P 1} \\
(11)\end{array}$ \\
\hline PUMP 2 & $W_{P 2}=\left(h_{7}-h_{6}\right)$ & (5) & $X_{\text {des }-P 2}=\left(h_{6}-h_{7}-T_{0}\left(s_{6}-s_{7}\right)\right)-W_{P 2}(12)$ \\
\hline HEATER & $y=\frac{h_{6}-h_{5}}{h_{2}-h_{5}}(6)$ & & $\begin{array}{c}X_{\text {des-He }}=h_{2}-h_{6}-T_{0}\left(s_{2}-s_{6}\right)+(1-y) \cdot\left(h_{5}-h_{2}\right. \\
\left.-T_{0}\left(s_{5}-s_{2}\right)\right)(13)\end{array}$ \\
\hline EFFICIENCY & $n_{I}=1-\frac{q_{\text {out }}}{q_{\text {in }}}$ & (7) & $n_{I I}=1-\frac{X_{\text {destroyed }}}{X_{\text {supplied }}}$ \\
\hline
\end{tabular}

\section{RESULTS AND DISCUSSIONS}

3.1 Case study 1: Energy analysis.

According to the results of the study of the first thermodynamic law, a significant decrease in both thermal efficiency and turbine work was obtained by increasing the pressure in the condenser, as shown in figure 3.

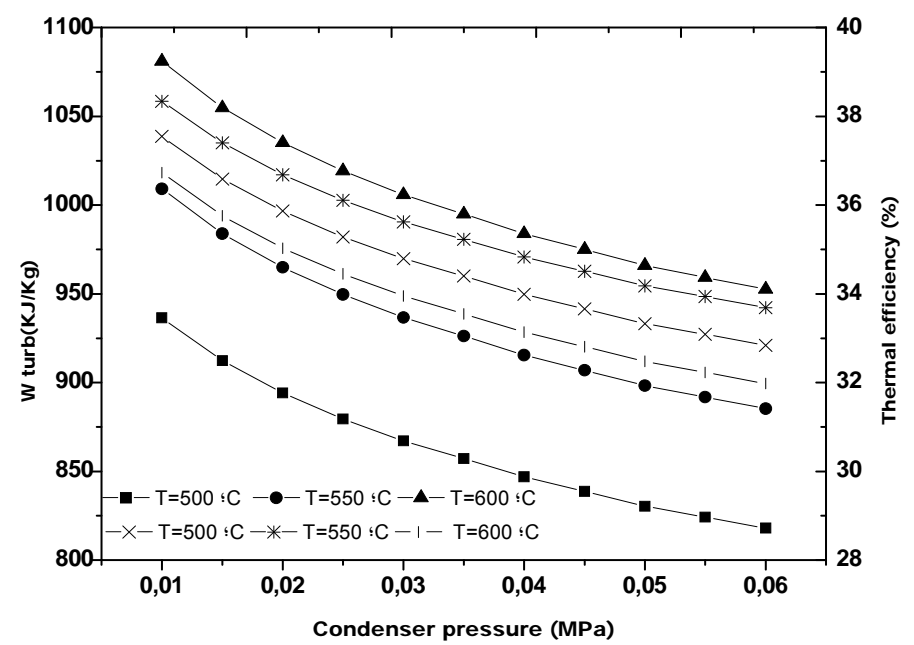

Fig. 3-Turbine work and thermal efficiency under 10 condenser pressures and 3 temperatures in the boiler. 
From the previous analysis, it was found that the maximum increase in thermal efficiency and turbine work was $12.94 \%$ and $12.65 \%$, respectively, at a temperature of $500^{\circ} \mathrm{C}$ in the boiler.

3.2Case Study 2: Exergetic analysis.

Afterwards,in the results of the exergy analysis, it was found that the destruction exergy rate of the boiler isdominant over all other irreversibilities in the cycle, as shown in Figure 4a, Figure 4b and Figure 4c, results that are in accordance with the literature [9].
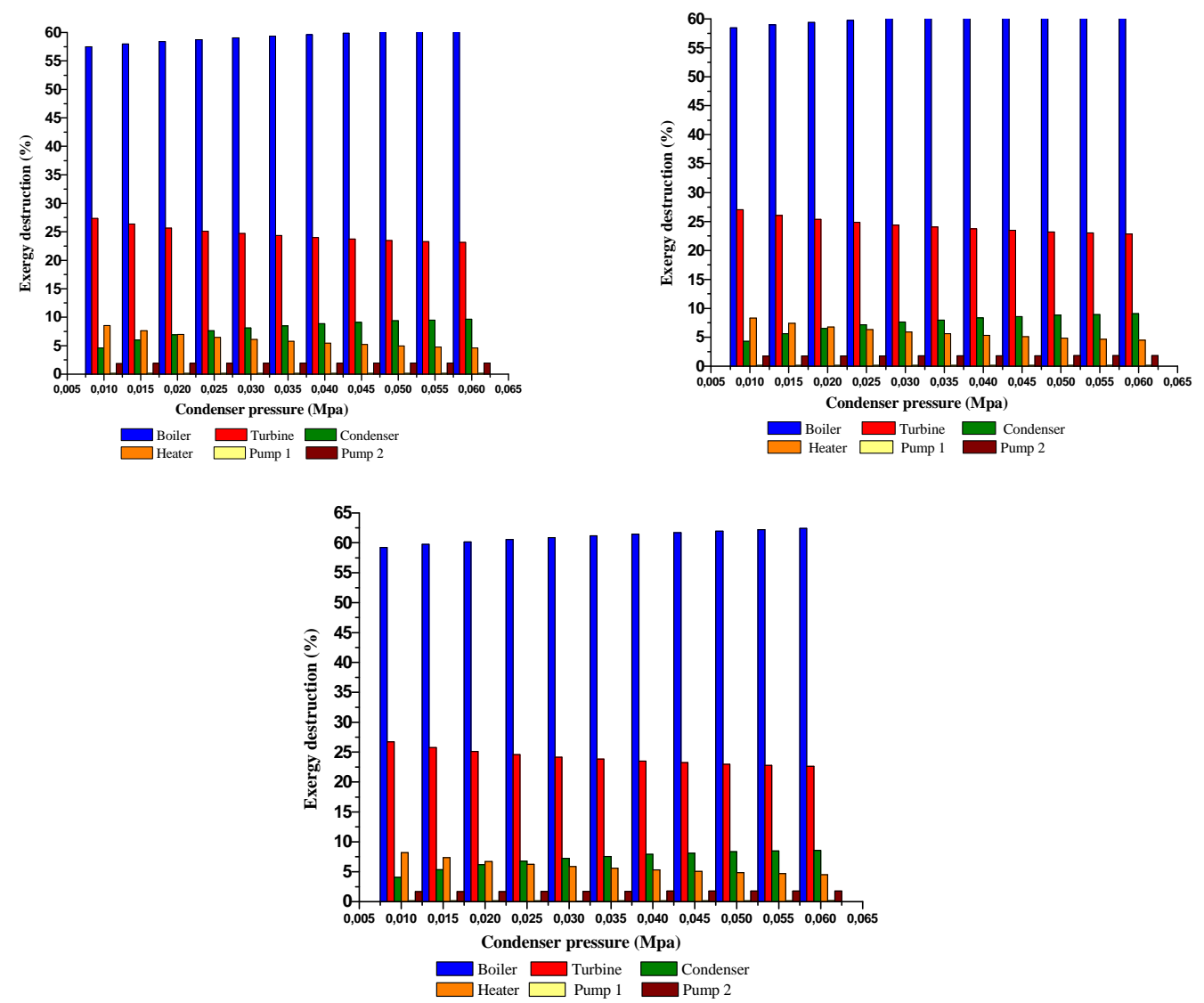

Fig. 4- Destroyed exergy by the components under, a) Boiler temperature of $500^{\circ} \mathrm{C}$, b) Boiler temperature of $550^{\circ} \mathrm{C}$, c) Boiler temperature of $600^{\circ} \mathrm{C}$

From the previous results, the maximum exergy destruction in the boiler was obtained when the temperature of this one was $600^{\circ} \mathrm{C}$, with a final increase $5.05 \%$ according to the variation of the condenser pressure. In the case of the turbine, a decrease $17.34 \%$ was obtained.Subsequently, the exergy efficiency compared to that of the first law increased as the pressure in the condenser increased.This is because the supplied exergy remained constant in all cases, while the total destroyed exergy decreased as shown in Figure 5.

Increasing the inlet temperature and pressure during the process of adding heat indirectly mean an enhancement in the drop pressure in the turbine. Therefore, the boilerdirectly increases the thermal efficiency of the cycle, that is, that an increase in temperaturegenerates greater advantage of expansion in the turbine, since the steam has higher internal energy. In addition, another way of increasing the regular temperature during the heat supply process isto increase the operating pressure of the boiler, which automatically raises the temperature atwhich the phase change occurs of the steam. This in turn raises the average temperature at which heat is transferredto the steam and thereby increases the thermal efficiency of the thermodynamics cycle. 


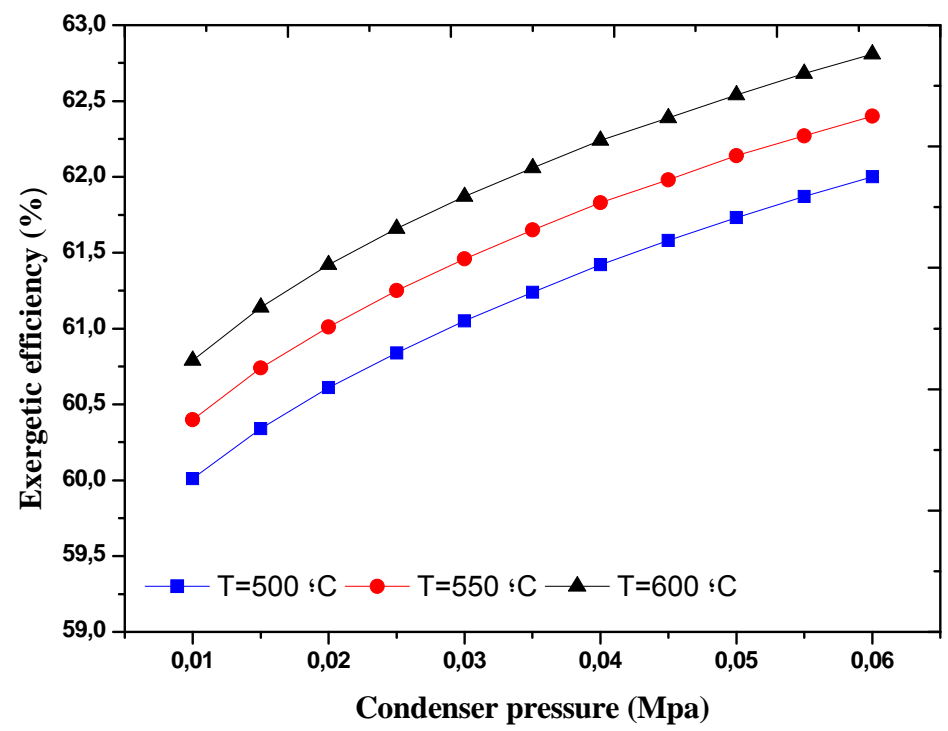

Fig. 5- Exergetic efficiency of the cycle under 10 condenser pressures and 3 temperatures in the boiler.

From the present analysis, it was found that the maximum increase in the exergetic efficiency was 3.21\%, with $600^{\circ} \mathrm{C}$ in the boiler, which is related to the law enthalpy in steam in the condenser that involve a large amount of energy transferred by work in the turbine.In practice the result obtained in this case study of the process is not totally real, because of the boiler will always need to supply more heat from the source than the one required to generate mechanical work under a reversible process.

\section{CONCLUSIONS}

In the present study it was found that a significant increase in the thermal and exergetic efficiency of a regenerative Rankine cycle is obtained when the pressure in the condenser decreases, however, it is not advisable to decrease it in large proportions because this is the same pressure in one of the turbine outlets, therefore, having low pressures in this state could cause damage to the blades of the turbine[21].Additionally, in all cases studied the exergy destruction rate of the boiler isdominant over all other irreversibilities in the cycle with $62.18 \%$, followed by the turbine with a maximum exergy destruction of $22.79 \%$, and finally $15.03 \%$ in the pumps, the heater and the condenser.

\section{ACKNOWLEDGMENT}

The authors would like to thank the Engineering Faculty and the Energy Efficiency Management research group of the Universidad del Atlántico (KAI) for their support in the development of this research, and the resources available in the Energy Efficiency laboratory of the same institution.

\section{REFERENCES}

[1] R. Shang, Y. Zheng, W. Shi, X. Wang, and Y. Zhang, “Fresh look and understanding on carnot cycle,” Energy Procedia, vol. 61, pp. 2898-2901, 2014.

[2] U. Lucia, “Carnot efficiency: Why?,” Phys. A Stat. Mech. its Appl., vol. 392, no. 17, pp. 3513-3517, 2013.

[3] Y. a. Cengel and M. E. Boles, “Termodinamica - Cengel 7th,” Termodinamica, p. 1456, 2011.

[4] R. F. Andres, “Corrosion in the Boiler,” Ind. \\& Eng. Chem., vol. 46, pp. 990-992, 1954.

[5] Lalatendu Pattanayak and Jaya Narayan Sahu and Pravakar Mohanty, “Combined cycle power plant performance evaluation using exergy and energy analysis,” Environ. Prog. I\& Sustain. Energy, vol. 36, pp. 1180-1186, 2017.

[6] M. Moran and H. Shapiro, Fundamentals of Engineering Thermodynamics. 2006.

[7] S. C. Kaushik, V. S. Reddy, and S. K. Tyagi, "Energy and exergy analyses of thermal power plants: A review," Renew. Sustain. Energy Rev., vol. 15, no. 4, pp. 1857-1872, May 2011.

[8] X.-T. Cheng and X.-G. Liang, “Applicability of the minimum entropy generation method for optimizing thermodynamic cycles," Chinese Phys. Soc. IOP Publ. Ltd, vol. 22, 2013.

[9] J. Soundhar, M. T. Durai, R. Vijay, and M. Siva, "Parametric Study and Analysis of Varying the Condenser Pressure in Thermal Power Plant,” vol. 3, no. Xii, pp. 181-189, 2015.

[10] A. Bejan, "Fundamentals of Exergy Analysis, Entropy Generation Minimization, and the Generation of Flow Architecture," Int. J. Energy Res., vol. 26, no. 7, 2002.

[11] T. J. Kotas, "Exergy criteria of performance for thermal plant: Second of two papers on exergy techniques in thermal plant analysis," Int. J. Heat Fluid Flow, vol. 2, no. 4, pp. 147-163, Dec. 1980.

[12] G. Tsatsaronis and M.-H. Park, "On avoidable and unavoidable exergy destructions and investment costs in thermal systems,” Energy Convers. Manag., vol. 43, no. 9-12, pp. 1259-1270, Jun. 2002.

[13] S. Kelly, G. Tsatsaronis, and T. Morosuk, "Advanced exergetic analysis: Approaches for splitting the exergy destruction into endogenous and exogenous parts,” Energy, vol. 34, no. 3, pp. 384-391, Mar. 2009. 
[14] M. Pons, "Irreversibility in energy processes: Non-dimensional quantification and balance,” J. Non-Equilibrium Thermodyn., vol. 29, no. 2, pp. 157-175, 2004.

[15] Y. Dementiev, L. Burulko, and E. Suvorkova, "Pedagogical Aspects of Applied Software Packages and Computer Technologies Use in Student’s Education,” Procedia - Soc. Behav. Sci., vol. 206, no. November, pp. 289-294, 2015.

[16] B. Manrique-Losada, G. P. Gasca-Hurtado, and M. C. Gómez Álvarez, "Assessment proposal of teaching and learning strategies in software process improvement,” Rev. Tec. la Fac. Ing. Univ. del Zulia, vol. 40, no. 1, pp. 133-143, 2017.

[17] R. Casallas, J. I. Davila, and J. P. Quiroga, “Enseñanza de la ingeniería de software por procesos instrumentados,” no. May, pp. 1-10, 2014.

[18] V. M. Nikita, S. S. Elena, and M. S. Ulyana, "Motivation System of Students and Teaching Staff of Higher Educational Institutions for Research Work Accomplishment,” Procedia - Soc. Behav. Sci., vol. 166, pp. 265-269, 2015.

[19] C. Landwehr et al., "Software Systems Engineering programmes a capability approach,” J. Syst. Softw., vol. 125, pp. 354-364, 2017.

[20] L. G. Obregon Quinones, L. F. Arrieta Viana, and G. E. Valencia Ochoa, "Thermal Design and Rating of a Shell and Tube Heat Exchanger Using a Matlab® GUI,” Indian J. Sci. Technol., vol. 10, no. 25, pp. 1-9, 2017.

[21] A. D. Kushwaha, A. Soni, and L. Garewal, "Critical Review paper of Steam Turbine Blades Corrosion and its Solutions,” Int. J. Sci. Res. Eng. Technol., vol. 3, no. 4, pp. 776-784, 2014.

\section{AUTHOR PROFILE}

Cristina Lizarazo Bohórquez born in Barranquilla, Colombia on September 25, 1997. She is a student in mechanical engineering at Universidad del Atlántico. In his undergraduate thesis, is working application of linear observers in thermodynamic processes at Universidad del Atlántico

Carlos Acevedo Peñaloza. Received a degree in Mechanical Engineering from Universidad Francisco de Paula Santander UFPS, located in Cucuta, Colombia in 1995. Master in Mechanical Engineering from Universidad de los Andes, Bogota, Colombia in 1997. Ph. D in Engineering from the Universidad Politecnica de Cataluna, Barcelona, España in 2005.

Guillermo Valencia Ochoa born in Barranquilla, Colombia. Is a full-time professor at the Universidad del Atlántico. Received a degree in Mechanical Engineering from Universidad del Norte, located in Barranquilla, Colombia in 2005. Master in Mechanical Engineering from Universidad del Norte, Barranquilla, Colombia in 2008. Ph. D in Engineering from the Universidad Pontificia Bolivariana, Medellin, Colombia in 2014. He is an assistant professor of the Mechanical Engineering Program, Specialization in Energy Efficient Management and Master in Energy Management at Universidad del Atlántico. 